\title{
Tribological Investigation of Self-Lubricated Al-SiC- Kaoline Hybrid Composite Under Dry, Oil and Nanofluids Lubricating Conditions Fabricated Through Spark Plasma Sintering Technique.
}

Venkatesh Vavilada ( $\nabla$ vssvenkateshnits@gmail.com )

National Institute of Technology Silchar https://orcid.org/0000-0001-8639-8707

Ashish B Deoghare

NIT Silchar: National Institute of Technology Silchar

\section{Research Article}

Keywords: SiC reinforcement, Spark Plasma Sintering, worn surface morphology, Nanofluid lubrication, Thermal conductivity

Posted Date: August 19th, 2021

DOI: https://doi.org/10.21203/rs.3.rs-808599/v1

License: (c) (i) This work is licensed under a Creative Commons Attribution 4.0 International License.

Read Full License 


\section{Abstract}

In this present study Al- $10 \%$ SiC- $X \%$ Kaoline (X= 0, 2, 4, 6, 8) HMMC synthesized by spark plasma sintering technique. The fabricated $\mathrm{HMMC}$ samples corresponding to maximum compression strength was subjected to tribological investigation under dry, oil and nanofluids lubricating conditions. Nanofluid lubricants were developed by incorporating $\mathrm{SiC}$ nanoparticles with weight percentages of $1 \mathrm{wt} \%, 1.5 \mathrm{wt} \%$ and $2 \mathrm{wt} \%$ into the soluble oil. The thermal conductivity was found to be increased with increasing the wt $\%$ of $\mathrm{SiC}$ nanoparticles and the maximum thermal conductivity of $0.771 \mathrm{~W} / \mathrm{m} . \mathrm{K}$ was obtained for the nanofluids with $2 \mathrm{wt} \% \mathrm{SiC}$ nanofluids. Sliding wear test was conducted on the pin-on-disc tribometer at $40 \mathrm{~N}$ load and sliding speed of 1500 r.p.m for a sliding of $180 \mathrm{~s}$. Results reveal that there was a significant effect of the lubricating conditions (dry, oil and nanofluids) on the wear and C.O.F of the HMMC pin surface. The minimum wear of 119 microns and minimum C.O.F of 0.11 was obtained for nanofluid with $2 \mathrm{wt} \% \mathrm{SiC}$ nanofluid lubricating conditions. SEM analysis of worn surface under dry and soluble oil lubricating conditions reveal the presence of microcracks and delaminations wear. However, worn surface with smooth grooves and absence of microcracks was identified under nanofluid lubricating conditions.

\section{Introduction}

The intrinsic properties of aluminium such as low density, high resistance to corrosion, better thermal conductivity and high strength to weight ratio made it suitable as a matrix material in MMC to fabricate components like automobile pistons, brake discs and automobile bodies

etc.,[1, 2]. However, the lower hardness and poor wear resistance of aluminium made limited applications in the tribological environment. Therefore, reinforcement particles were incorporated into the aluminium matrix to enhance the mechanical and tribological properties of the material [3]. Reinforcing ceramic $\mathrm{Al}_{2} \mathrm{O}_{3}$, SiC, TiC and WC into the softer aluminium matrix enhance the wear resistance, creep and yield point of the material [4]. Among available ceramic reinforcements, $\mathrm{SiC}$ reinforced MMC exhibits better mechanical and anti-wear characteristics [5]. However, Incorporating single SiC reinforcement enhances the brittleness and C.O.F to the composite specimen. To eradicate this difficulty, ductile and selflubricated secondary reinforcements were added to the aluminium matrix material [6]. Despite all fabricating methods available, the Spark plasma sintering technique was adopted due to higher sintering rate, lesser porosity defects and the possibility of obtaining nearly net-shaped products [7, 8]. Amra et al., [9] studied the wear and frictional behaviour of $\mathrm{Al} 5083 / \mathrm{CeO}_{2} / \mathrm{SiC} \mathrm{HMMC}$ and concluded that minimum wear rate of $4 \times 10^{-3} \mathrm{~mm}^{3} / \mathrm{m}$ obtained for Al5083/ $\mathrm{CeO}_{2} / \mathrm{SiC} \mathrm{HMMC}$ when compared to Al5083/SiC MMC due to the existence of self-lubricating property of the $\mathrm{CeO}_{2}$ reinforcement particles. Umanath et al., [10] investigated dry sliding wear characteristics of $\mathrm{Al} 6061 / \mathrm{SiC} / \mathrm{Al}_{2} \mathrm{O}_{3} \mathrm{HMMC}$ against the counter steel disc. Results reveal that the $15 \%$ reinforced HMMC exhibits superior anti-wear performance than the $5 \%$ reinforced HMMC. In addition to this, the worn surface of the HMMC sample confirms the presence of tear ridges and cracked $\mathrm{SiC}$ and $\mathrm{Al}_{2} \mathrm{O}_{3}$ reinforcement particles indicating combined ductile and brittle 
fracture of HMMC specimen. Halil Karakoc et al., [11] examined the wear behaviour of $\mathrm{Al} 6061 / \mathrm{SiC} / \mathrm{B}_{4} \mathrm{C}$ $\mathrm{HMMC}$ composite fabricated through powder metallurgy technique. Results concluded that a lower rate of $1.4 \times 10^{-13} \mathrm{~mm}^{3} / \mathrm{m}$ was achieved for the Al6061/9\% $\mathrm{B}_{4} \mathrm{C} / 3 \% \mathrm{SiC}$ HMMMC for $100 \mathrm{~m}$ sliding distance at an applied load of $15 \mathrm{~N}$. Mehta et al.,[12] studied the wear properties of aluminium and magnesium alloys under wet and dry lubricating environments and claimed that wear rate of the fabricated pin materials depends on the lubricating conditions. Further, to enhance the wear and thermal properties, nanofluids with nanoparticles of higher thermal conductivity were used as lubricants [13]. Singh et al., [14] studied the tribological behavior of Al6061/SiC/Gr HMMC under MWCNT-in-oil and surfactant functionalized MWCNT-in-oil lubricating conditions. Results reveal that wear rate of the HMMC pin specimen was reduced by 5 and 6 times respectively for the respective lubricating conditions due to the

formation of tribofilm and the enhanced retaining stability of the lubricants between the matting surfaces.

From the above literature, it was concluded that limited work was carried on the tribological behaviour of the aluminium HMMC reinforced with naturally available reinforcements. Kaoline is a naturally available clay material that contains oxides of $\mathrm{Al}, \mathrm{Si}, \mathrm{Zn}, \mathrm{Mg}$ and Fe which improves the mechanical and anti-wear characteristics of the aluminium matrix [15]. In addition to this, kaoline clay contains self-lubricating properties and the presence of magnesium in the kaoline clay improves the wettability between the interface particles [16]. Therefore, In this present study, an attempt has been made to investigate the tribological behaviour of the Spark Plasma Sintered Al-SiC-Kaoline HMMC under the dry, wet and nanofluids with $\mathrm{SiC}$ nanoparticles lubricating conditions.

\section{Materials And Methods}

The Aluminium powder (purity 99\%) mixed with a pre-measured quantity of SiC reinforcement having a particle size less than $30 \mu \mathrm{m}$ (refer Fig. 1 (a)) and kaoline reinforcement having a particle size less than $30 \mu \mathrm{m}$ (refer Fig. 1 (b)) to fabricate Al-10\% SiC-X \% Kaoline (X= 0, 2, 4, 6, 8) HMMC specimens. Aluminium powder was selected as a matrix material due to the existence of intrinsic properties such as lesser density ( $2.7 \mathrm{~g} / \mathrm{c} . \mathrm{c})$, high strength to weight ratio and better corrosion resistance [17]. SiC was used as primary reinforcement as it possesses high compression strength (3900 MPa), higher hardness (280 $\mathrm{BHN})$ and high melting point $\left(2730^{\circ} \mathrm{C}\right)[18]$. The existence of harder ceramic reinforcements and the presence of higher melting temperature $\left(740^{\circ} \mathrm{C}\right)$ makes kaoline clay as the suitable secondary reinforcement in this study $[19,20]$. The sequence of processing steps followed during the fabrication of composite specimens was shown in Fig. 2. Initially, The measured quantity of matrix and reinforcement powders were loaded in chromium hardened steel vial with a 10:1

ball to powder ratio. $1 \mathrm{wt} \%$ stearic acid was mixed with these powders to avoid the cold welding between the powder particles. Ball milling was performed in RESTECH 100 planetary ball mill at a speed of 300 $\mathrm{rpm}$ for $3 \mathrm{~h}$ to disperse the reinforcements uniformly throughout the matrix and to induce the strain hardening effect in the powder particles. The entire ball milling setup was sealed with inert gas (Ar) 
atmosphere to prevent the contamination and oxidation of aluminium powder during the milling process $[21,22]$. These milled powders were charged into a graphite die and subjected to the simultaneous

application of $35 \mathrm{MPa}$ pressure and $2 \mathrm{KW}$ power supply by using an automated SPS machine (FCT syateme, HP D-5 type, Rauenstein, Germany) [23]. To measure the sintering temperature during the SPS process, a thermocouple was inserted into the graphite die through a drilled hole. A thin graphite sheet was wrapped around the inner walls of the die for easy ejection of sintered specimens and to reduce the friction between the die wall and the composite specimen [24].

\subsection{Preparation of SiC Nanofluids}

$\mathrm{SiC}$ nanoparticles having a size less than $100 \mathrm{~nm}$ were procured from Paraswamanai metals Mumbai. $\mathrm{SiC}$ nanofluids were prepared by using a two-step method. The SiC nanoparticles were charged into the base fluid (ethylene glycol) by varying the weight percentage of SiC nanoparticles i,e., 1 wt. \%, 1.5 wt. \% and $2 \mathrm{wt} . \%$. This mixture was subjected to the stirring process by using a magnetic stirrer at a speed of $650 \mathrm{rpm}$ [13]. An ultrasonic processor (FS-300 N, $300 \mathrm{~W}$, and $24 \mathrm{~Hz}$ ) with a probe diameter of $8 \mathrm{~mm}$ was utilized for the uniform distribution of $\mathrm{SiC}$ nanoparticles in the Ethylene glycol mixture. The ultrasonic sonication process was done for $15 \mathrm{~h}$ for each sample in a $100 \mathrm{ml}$ beaker kept at room temperature as shown in Fig. 3 [25].

\section{Characterization Techniques}

\subsection{Measurement of thermal conductivity for SiC Nanofluids}

The Thermal conductivity of nanofluids takes part a significant role in absorbing and transferring heat between the contact surfaces. In this study, Hot disc thermal constant analyzer was employed to compute the thermal conductivity of $\mathrm{SiC}$ nanofluids. The thermal conductivity of $\mathrm{SiC}$ nanofluids was assessed at $25^{\circ} \mathrm{C}$ by varying the $\mathrm{SiC}$ nanoparticles concentration such as $1 \mathrm{wt} . \%, 1.5 \mathrm{wt} . \%$ and $2 \mathrm{wt} . \%$. Figure 4 depicts the variation of thermal conductivity of $\mathrm{SiC}$ nanofluids with wt.\% of SiC nanoparticles. The thermal conductivity of nanofluids was found to be increased with an increase in wt. \% of SiC nanoparticles and the

maximum thermal conductivity of $0.771 \mathrm{~W} / \mathrm{mk}$ was obtained at $2 \mathrm{wt} \%$. SiC nanoparticles. This enhancement in thermal conductivity was attributed due to the increment in the incorporation of high thermal conductive SiC nanoparticles in a fixed volume of ethylene glycol [26]. Incorporation of SiC nanoparticles of more than $2 \mathrm{wt}$.\% leads to the agglomerations of the nanoparticles which are prone to reduction in thermal conductivity of nanofluids as shown in Fig. 5.

\subsection{Characterization of HMMC specimens}

The elemental phases present in the HMMC samples was confirmed by using a fully automated PANanalytical X-Ray Diffractometer by applying $40 \mathrm{KV}$ voltage and $20 \mathrm{~mA}$ current. XRD patterns were 
considered in the angle (20) ranging from $20^{\circ}$ to $90^{\circ}$. The morphology and distribution of reinforcement particles were identified through Carl Zeiss EVO 50 high resolution scanning electron microscope integrated with Energy Dispersive X-ray (EDX) analyzer. The microhardness of the synthesized HMMC specimens was determined according to ASTM E384-16 standards by applying a load of $25 \mathrm{~N}$ for a dwell time of $15 \mathrm{~s}$ [27]. HV 0.1 microhardness values were obtained from the ECONOMET VH1MD hardness tester and the corresponding VHN values taken from the hardness conversion chart. Compression test was conducted on micro universal testing machine M30 model as per ASTM E9 standards. The average of five readings was taken for each HMMC sample for better accuracy of hardness and compression results [6].

\subsection{Tribological testing of HMMC samples}

The tribological properties of the fabricated $\mathrm{Al}-10 \%$ SiC- $4 \%$ Kaoline HMMC under dry, wet and nanofluids lubricating conditions were determined by conducting a wear test on the computer-aided pin-on-disc tribometer (Cenlub Industries Ltd. India) as per ASTM G 99 standards [1]. The cylindrical composite specimens having $40 \mathrm{~mm}$ length and $8 \mathrm{~mm}$ dia were placed in the perpendicular direction against the EN 31 (63 HRC) steel disc counter body. The wear test was conducted under a constant load of $40 \mathrm{~N}$ and a rotating speed of 1500 r.p.m while considering a track radius of $50 \mathrm{~mm}$ [13]. The wear loss of the pin material in microns was recorded by using a linear variable differential transducer (LVDT) having the least count of $1.0 \mathrm{~mm}$. Acetone is used to clean the wear debris present on the counter steel disc after each wear test. The fabricated HMMC specimens for the tribological and compression test were shown in Fig. 6.

\section{Results And Discussion}

\subsection{Microstructural investigation of fabricated HMMC specimens}

Figure 7 (a-d) depicts the SEM micrographs for the SPS composite specimens. It was clear that the uniform distribution of reinforcements and absence of agglomerations were confirmed for the composite specimens having Al-10\% SiC- 2\% Kaoline, Al-10\% SiC- 4\% Kaoline, Al-10\% SiC- 6\% Kaoline compositions ( refer Fig. $7(\mathrm{a}-\mathrm{c})$ ). However, incorporation of kaoline reinforcement beyond $6 \%$ leads to formation clusters or agglomerations at the interfaces of $\mathrm{SiC}$ and kaoline reinforcements as shown in Fig. 7 (d). XRD analysis for the corresponding agglomerated specimen reveals the presence of a high-intensity peak at $43^{0}$. The corresponding $\mathrm{Al}_{2} \mathrm{Cu}$ element was identified with JCPDS file number 25 - 0012 (refer Fig. 9). A similar $\mathrm{Al}_{2} \mathrm{Cu}$ peak was identified by the researchers Anbukkarasi $\mathrm{R}$ et al., [28], Shakir Gatea et al., [29] and Hailan Ma et al., [30] in their studies. The presence of SiO2 (JCPDS file number 46-1045 [31, 32]), $\mathrm{Al}_{2} \mathrm{O}_{3}$ (JCPDS file number 00-046-1212 [33]), $\mathrm{TiO}_{2}$ (JCPDS file number 21-1276 [34]), Cao (JCPDS file number 00-037-1497 [35]) and MgO (JCPDS file number 59-7746 [36]) peaks in the fabricated HMMC were confirmed through XRD analysis. The existence of difference in coefficient of thermal expansions of the 
agglomerations and the reinforcement particles tends to decrease the load-bearing capability of the HMMC and causes the degradation of strength of the composite material [37, 38]. In the SPS process, due to the simultaneous application of heat and pressure over a short period of time in presence of vacuum, the possibility of pores formation and oxidation of HMMC was minimized [39]. The elemental mapping of the $\mathrm{Al}-10 \% \mathrm{SiC}-8 \%$ Kaoline is shown in Fig. 8, Which represents the presence and uniform dispersion of Aluminium (Al), Oxygen (O), Silicon (Si), Magnesium (Mg), Carbon (C), Titanium (Ti), Iron $(\mathrm{Fe})$, Copper $(\mathrm{Cu})$ and $\mathrm{Zinc}(\mathrm{Zn})$. The existence of these elements confirms the presence of $\mathrm{Al}_{2} \mathrm{O}_{3}, \mathrm{SiO}_{2}$, $\mathrm{MgO}, \mathrm{Fe}_{2} \mathrm{O}_{3}$ and $\mathrm{TiO}_{2}$ compounds in the kaoline reinforcement. The elemental mapping of copper and aluminium represents the presence of $\mathrm{Al}_{2} \mathrm{Cu}$ intermetallic compound in the $\mathrm{Al}-10 \% \mathrm{SiC}-8 \%$ Kaoline $\mathrm{HMMC}$ specimen.

\subsection{Mechanical properties of HMMC samples \\ 4.1.1 Variation of Hardness of HMMC with \% reinforcement}

Figure 10 depicts the variation of the hardness of $\mathrm{HMMC}$ with \% of kaoline reinforcement particles. The hardness of the HMMC sample increases from $130 \mathrm{VHN}$ for $\mathrm{Al}-10 \% \mathrm{SiC}$ to $169 \mathrm{VHN}$ for $\mathrm{Al}-10 \% \mathrm{SiC}-8 \%$ Kaoline reinforced HMMC. i,e $30 \%$ enhancement in hardness for the Al-10\% SiC-8\% Kaoline HMMC then the Al-10\% SiC MMC. The increase in hardness was attributed due to the existence of magnesium element in the kaoline clay, which improves the wettability between the matrix and reinforcement particles. This phenomenon further enhances the load transfer from the adjacent particles during the indentation test which causes improvement in Vickers hardness of the HMMC [40]. In addition to this, the Incorporation of ceramic $\mathrm{SiC}$ and Kaoline ( Contains $\mathrm{Al}_{2} \mathrm{O}_{3}, \mathrm{SiO}_{2}$ ) into the ductile aluminium matrix and uniform dispersion of these reinforcement particles in the aluminium matrix improves the resistance to the indentation during the hardness test. The obtained hardness values were comparatively higher than the results obtained by the researchers Manikandan et al., [41] and Abhijith Bhowmick et al., [42] in their studies.

\subsubsection{Variation of Compression strength of HMMC specimens with \% reinforcement}

The variation of compression strength of the HMMC with \% composition was shown in Fig. 11. It was found that the compression strength of the Al- $10 \%$ SiC- 6 \% Kaoline HMMC composite specimen was increased by $34.88 \%$ than the HMMC sample with $\mathrm{Al}-10 \% \mathrm{SiC}$ reinforcements. The maximum compression strength of $290 \mathrm{MPa}$ was noticed for Al-10\% SiC-6\% Kaoline HMMC. The increase in compression strength was attributed due to the incorporation of ceramic $\mathrm{SiC}$ and Kaoline $\left(\mathrm{Al}_{2} \mathrm{O}_{3}, \mathrm{SiO}_{2}\right)$ reinforcements which improves the grain boundaries around the matrix and reinforcement interfaces. These grain boundaries act as barriers for the movement of microcrack propagation during the compression strength, which causes the enhancement of compression strength of HMMC up to the addition of $6 \%$ kaoline reinforcement $[43,44]$. In addition to this, the reinforced SiC and Kaoline particles hinder the dislocation motion near the interfaces. Consequently, dislocations pile-up occurs which enhances the strength of the material by the Orowan mechanism [45]. However the incorporation of kaoline reinforcement more than $6 \%$ leads to a decrement in compression strength of the composite due 
to the formation of $\mathrm{Al}_{2} \mathrm{Cu}$ agglomerations along with the interfaces of matrix and reinforcement particles as shown in Fig. 9. These agglomerations

increases the slip planes near the interfaces and atoms along the slip planes found the path for movement even at the lower compression loads $[46,47]$.

\subsection{Tribological properties of HMMC samples 4.2.1 Wear rate}

The variation of wear of HMMC specimens under different lubricating conditions with time is shown in Fig. 12. It was observed that the dispersion of $\mathrm{SiC}$ nanofluids between the contact surfaces significantly reduces the wear of the HMMC pin surface when compared to dry and oil lubricating conditions. The wear of the HMMC pin surface at an applied of $40 \mathrm{~N}$ and sliding time of $180 \mathrm{~s}$ under $2 \mathrm{wt} \% \mathrm{SiC}$ nanofluids lubricating condition was considerably reduced by $60.27 \%$ and $71.4 \%$ when compared to wear under dry and oil lubricating conditions respectively. The minimum wear of 140 microns for $2 \mathrm{wt} \%$ $\mathrm{SiC}$ nanofluid lubrication was attributed due to the formation of tribolayer at the pin and disc interfaces [48-50]. This tribolayer acts as a barrier to avoid the rubbing of the pin against the counter disc and leads to lift up the pin from the disc surface causing apparent negative wear [13]. However, with a further increase in the sliding time from $180 \mathrm{~s}$, the generated heat between

the interfaces get ruptured the tribofilm which is prone to a higher wear rate for the HMMC pin surface. The ability to stay the SiC nanofluids between the interfaces of HMMC pin surface and counter steel disc accounted for minimizing direct contact between the mating surfaces. In addition to this, the existed SiC nanoparticles between the interfaces may absorb the generated heat at the contact surfaces of the HMMC pin and counter disc surface which consequently reduces the plastic deformation and causes a reduction in wear of the HMMC pin surface.

\subsubsection{Co-efficient of friction}

Figure 13 depicts the variation of C.O.F with time under dry, oil lubrication and nanofluids lubricating environment. The C.O.F values were found to be decreased with an increase in sliding time for all the lubricating conditions. The highest value of C.O.F (0.30) was noticed under dry lubrication conditions, whereas the minimum C.O.F (0.11) was obtained for nanofluids with $2 \mathrm{wt} \% \mathrm{SiC}$ nanoparticle lubricating condition. The presence of self-lubricated kaoline clay, which acts as a solid lubricant and forms the solid lubricant-rich film on the contact surfaces results in decreasing friction by avoiding metal-to-metal contact of

tribosurfaces [51]. In addition to this, the existence of rolling action due to the presence of SiC nanoparticles and the formation of wear debris which contains $\mathrm{Al}_{2} \mathrm{O}_{3}, \mathrm{Fe}_{2} \mathrm{O}_{3}, \mathrm{CaO}, \mathrm{MgO}$ and $\mathrm{SiO}_{2}$ helps to further reduction in C.O.F $[52,53]$.

\subsubsection{Worn surface morphology}


Figure 14 depicts the SEM and corresponding EDX spectra for the worn surfaces of Al- $10 \%$ SiC-6\% Kaoline HMMC pins after a sliding period of 180 s under dry, oil and nanofluid with 2 wt\% SiC nanoparticles lubrication conditions respectively. Continuous grooves parallel to the sliding direction were observed under all lubricating conditions due to the ploughing action of the ceramic SiC and kaoline reinforcement particles onto the counter EN31 steel disc. In the case of dry condition ( refer Fig. 14(a) ), the existence of direct contact between the asperities between the HMMC pin and counter disc surface leads to thermal softening of the pin surface and causes severe wear of the HMMC pin under this dry condition [54]. In addition to this, the hard ceramic reinforcement particles from the composite pin surface debonded and fragmented into several smaller abrasive particles. The detached ceramic particles from the composite pin surface left sites for the microcrack initiation and propagation that causes delamination wear of the HMMC pin surface. Figure 14 (a) represents

the presence of microcracks and detached bulk surface in form of laminates which are the characteristics of the delaminative wear mechanism. The localized stress concentration around the asperities contact depends on the applied load and this, in turn, affects the wear of the pin surface.

Figure 14 (b) depicts the SEM micrograph of the worn pin surface under soluble oil lubrication. It was clear that the worn surface with many thick and deep furrows was observed. However, the worn surface was somewhat smoother when compared to dry conditions. The lesser wear rate in oil lubrication was attributed due to the decrease in asperities contact in the presence of soluble oil which promotes severe wear regime to mild wear regime [55]. In addition to this, the soluble oil between the asperities decreases the temperature rise which leads to a decrease the friction. During sliding, the wear debris was washed out in soluble oil lubrication condition thereby, the chances of third body abrasion and the oxide formation was minimized compared to dry lubricating condition.

The presence of SiC nanoparticles under nanofluids with 2 wt\% nanoparticles lubricating conditions converts sliding contact into rolling contact of interface surfaces which results in smoother furrows and grooves on the worn surface of HMMC pin as shown in Fig. 14 (c). The SiC nanoparticles create abrasive action between the interfaces which establishes a polishing effect. The combination of polishing and rolling phenomenon leads to decrease in the C.O.F up to the incorporation of $2 \mathrm{wt} \% \mathrm{SiC}$ nanoparticles. However, the Incorporation of more than 2 wt \% SiC nanoparticles shows the formation of clusters which reduces the polishing and rolling effects. Mending is the property of SiC nanoparticles that can be squeezed and deposited into the surface flaws causing lower wear in nanofluids with 2 wt\% SiC nanoparticles lubricating condition. Hence, rolling, polishing and mending are the main factors for enhanced anti-wear and anti-friction characteristics under these conditions.

\section{Conclusions}

In this present work tribological properties of spark plasma sintered $\mathrm{Al}-10 \% \mathrm{SiC}-4 \%$ Kaoline HMMC under dry, oil lubrication and nanofluids with SiC nanoparticles were investigated. The conclusions of the present study were summarized below. 
1. The Al-SiC-Kaoline HMMC with uniform distribution of reinforcements were fabricated successfully by using spark plasma sintering process.

2. The thermal conductivity of the base fluids was increased with the addition of SiC nanoparticles. The maximum thermal conductivity value of $0.771 \mathrm{~W} / \mathrm{m} . \mathrm{K}$ was obtained for the nanofluids with $2 \mathrm{wt} \%$ $\mathrm{SiC}$ nanoparticles. The higher thermal conductivity of these nanofluids enhances the heat removal rate which is generated between the mating surfaces.

3. The maximum compression strength of $290 \mathrm{MPa}$ was noticed for $\mathrm{Al}-10 \% \mathrm{SiC}-6 \%$ Kaoline. Therefore, a Tribological study was performed at this \% of reinforcements (i,e Al- $10 \%$ SiC-6\% Kaoline) under dry, oil lubrication and nanofluids with $2 \mathrm{wt} \%$ nanofluids lubricating condition.

4. From the tribology test, It was confirmed that the minimum wear for $\mathrm{Al}-10 \% \mathrm{SiC}-6 \%$ Kaoline HMMC was obtained under nanofluids lubricating conditions when compared to dry and oil lubricating conditions. The minimum wear of 119 microns and minimum C.O.F of 0.11 was obtained under nanofluids with $2 \mathrm{wt} \%$ nanofluid lubricating condition after sliding for $180 \mathrm{~s}$ at an applied load of 40 $\mathrm{N}$.

5. SEM micrographs of the worn surface of the HMMC pin reveals the presence of smooth grooves and the absence of microcracks under nanofluids lubricating conditions. However, microcracks, groves and delamination of the worn surface were obtained under dry and oil lubricating conditions.

\section{Declarations}

Acknowledgements Authors like to thank Central Instrumentation Facility at National Institute of Technology Silchar for XRD analysis. The authors also would like to appreciate the Advance centre for Material Science at Indian Institute of Technology Kanpur for SEM and EDS analysis.

\section{Author's Contribution}

V.S.S Venkatesh carried out the fabrication, Mechanical characterization of composite samples and Drafted the initial version of the manuscript. Ashish B Deoghare Reviewed and Edited the prepared manuscript. All authors read and approved the final manuscript.

\section{Data Availability}

Authors confirm that the entire data obtained during the Experiment was included in this available manuscript.

Funding Statement Not applicable.

\section{Conflict of interest}

Authors declared that they have no conflict of interest.

Ethical Approval Ethics Approval All experiments were conducted ethically and no issues regarding ethical issues arouse during the experiments or the manuscript confection. 
Compliance with Ethical Standards The Authors declare that they don't have known personal relationships or competing financial interest that could have appeared to influence the work reported in this manuscript.

Research Involving Human Participants and/or Animals Not applicable

Informed Consent Not applicable.

\section{Consent to Participate}

All the Authors are happily agree to contribute in this research work.

\section{Consent for Publication}

Consent was obtained from all authors to publish this manuscript. All the authors read and approved this manuscript to publish this article.

\section{References}

1. Surya MS, Prasanthi G, Gugulothu SK (2021) Investigation of Mechanical and Wear Behaviour of Al7075/SiC Composites Using Response Surface Methodology. Silicon. https://doi.org/10.1007/s12633-020-00854-y

2. Bhowmik A, Chakraborty D, Dey D, Biswas $A$ (2019) Investigation on wear behaviour of Al7075-SiC metal matrix composites prepared by stir casting. In: Materials Today: Proceedings. Elsevier Ltd, pp 2992-2995

3. Ramanathan A, Krishnan PK, Muraliraja R (2019) A review on the production of metal matrix composites through stir casting - Furnace design, properties, challenges, and research opportunities. J Manuf Process 42:213-245. https://doi.org/10.1016/j.jmapro.2019.04.017

4. Singh J, Chauhan A (2016) Overview of wear performance of aluminium matrix composites reinforced with ceramic materials under the influence of controllable variables. Ceram Int 42:56-81. https://doi.org/10.1016/j.ceramint.2015.08.150

5. Radhika N, Karthik R, Gowtham S, Ramkumar S (2019) Synthesis of Cu-10Sn/SiC Metal Matrix Composites and Experimental Investigation of its Adhesive Wear Behaviour. Silicon 11:345-354. https://doi.org/10.1007/s12633-018-9848-6

6. Venkatesh VSS, Deoghare AB (2021) Modelling and Optimisation of Wear Parameters for Spark Plasma Sintered Al - SiC - Kaoline Hybrid Composite Modelling and Optimisation of Wear Parameters for Spark Plasma Sintered Al - SiC - Kaoline Hybrid Composite. Adv Mater Process Technol 00:1-19. https://doi.org/10.1080/2374068X.2021.1939561

7. Surya MS, Prasanthi G (2018) Tribology in Industry Tribological Behaviour of Aluminum Silicon Carbide Functionally Graded Material. 40:247-253. https://doi.org/10.24874/ti.2018.40.02.08 
8. Sattari S, Jahani M, Atrian A Effect Of Volume Fraction Of Reinforcement And Milling Time On Physical And Mechanical Properties Of Al7075-Sic Composites Fabricated By Powder Metallurgy Method. Powder Metall Met Ceram 56:. https://doi.org/10.1007/s11106-017-9896-2

9. AMRA M, RANJBAR K, HOSSEINI SA (2018) Microstructure and wear performance of Al5083/CeO2/SiC mono and hybrid surface composites fabricated by friction stir processing. Trans Nonferrous Met Soc China (English Ed 28:866-878. https://doi.org/10.1016/S1003-6326(18)64720$X$

10. Umanath K, Palanikumar K, Selvamani ST (2013) Analysis of dry sliding wear behaviour of Al6061/SiC/Al20 3 hybrid metal matrix composites. Compos Part B Eng 53:159-168. https://doi.org/10.1016/j.compositesb.2013.04.051

11. Halil K, Ismail OI, Sibel D, Ramazan Çi (2019) Wear and mechanical properties of Al6061/SiC/B4C hybrid composites produced with powder metallurgy. J Mater Res Technol 8:5348-5361. https://doi.org/10.1016/j.jmrt.2019.09.002

12. Mehta DS, Masood SH, Song WQ (2004) Investigation of wear properties of magnesium and aluminum alloys for automotive applications. 156:1526-1531. https://doi.org/10.1016/j.jmatprotec.2004.04.247

13. Kharb SS, Khatkar SK, Charak A, Thakur A (2021) Tribological Investigation of AZ91/SiC Magnesium Hybrid Composite under Dry, Oil and Nanofluids Lubricating Conditions. Silicon 13:1313-1323. https://doi.org/10.1007/s12633-020-00520-3

14. Singh $H$, Bhowmick H (2020) Tribology International Lubrication characteristics and wear mechanism mapping for hybrid aluminium metal matrix composite sliding under surfactant functionalized. Tribol Int 145:106152. https://doi.org/10.1016/j.triboint.2019.106152

15. Venkatesh VSS, Deoghare AB (2020) Fabrication and mechanical behaviour of Al-Kaoline metal matrix composite fabricated through powder metallurgy technique. Mater Today Proc. https://doi.org/10.1016/j.matpr.2020.10.021

16. Dědková K, Janíková B, Matějová K et al (2015) Preparation, characterization and antibacterial properties of $\mathrm{ZnO} /$ kaoline nanocomposites. J Photochem Photobiol B Biol. https://doi.org/10.1016/j.jphotobiol.2015.03.034

17. Shirvanimoghaddam $\mathrm{K}$, Khayyam $\mathrm{H}$, Abdizadeh $\mathrm{H}$ et al (2016) Boron carbide reinforced aluminium matrix composite: Physical, mechanical characterization and mathematical modelling. Mater Sci Eng A 658:135-149. https://doi.org/10.1016/j.msea.2016.01.114

18. Venkatesh VSS, Deoghare AB (2021) Microstructural Characterization and Mechanical Behaviour of $\mathrm{SiC}$ and Kaoline Reinforced Aluminium. Metal Matrix Composites Fabricated Through Powder Metallurgy Technique

19. Nasr Isfahani MJ, Payami F, Asadabad MA, Shokri AA (2019) Investigation of the effect of boron carbide nanoparticles on the structural, electrical and mechanical properties of Al-B4C nanocomposites. J Alloys Compd 797:1348-1358. https://doi.org/10.1016/j.jallcom.2019.05.188 
20. Muralidharan N, Chockalingam K, Dinaharan I, Kalaiselvan K (2018) Microstructure and mechanical behavior of AA2024 aluminum matrix composites reinforced with in situ synthesized ZrB2 particles. J Alloys Compd 735:2167-2174. https://doi.org/10.1016/j.jallcom.2017.11.371

21. Manohar G, Pandey KM, Ranjan Maity S (2020) Effect of compaction pressure on mechanical properties of AA7075/B4C/graphite hybrid composite fabricated by powder metallurgy techniques. In: Materials Today: Proceedings. Elsevier Ltd, pp 2157-2161

22. Venkatesh VSS, Deoghare AB (2021) Effect of Particulate Type Reinforcements on Mechanical and Tribological Behavior of Aluminium Metal Matrix Composites: A Review. In: Pandey KM, Misra RD, Patowari PK, Dixit US (eds) Recent Advances in Mechanical Engineering. Springer Singapore, Singapore, pp 295-303

23. Saheb N (2013) Spark plasma and microwave sintering of Al6061 and Al2124 alloys. Int J Miner Metall Mater V 20:. https://doi.org/10.1007/s12613-013-0707-6

24. Saheb N, Hakeem AS, Khalil A et al (2013) Synthesis and spark plasma sintering of Al-Mg-Zr alloys. J Cent South Univ 20:7-14. https://doi.org/10.1007/s11771-013-1452-8

25. Ezekwem C, Dare A (2020) Thermal and electrical conductivity of silicon carbide nanofluids. Energy Sources, Part A Recover Util Environ Eff 1-19. https://doi.org/10.1080/15567036.2020.1792591

26. Thakur A, Manna A, Samir S (2020) Multi-Response Optimization of Turning Parameters during Machining of EN-24 Steel with SiC Nanofluids Based Minimum Quantity Lubrication. Silicon 12:7185. https://doi.org/10.1007/s12633-019-00102-y

27. Sutharsan S, Senthilkumar P, Koodalingam B et al (2021) Analysis of mechanical behavior of Al 6061 metal matrix with boron carbide and graphite. Mater Today Proc. https://doi.org/10.1016/j.matpr.2021.03.354

28. Anbukkarasi R, Kailas SV (2020) Influences of shape of the new interfaces and morphology of the intermetallics on mechanical properties of aluminum AA2024-pure copper joints by friction stir welding. Int J Adv Manuf Technol 106:5071-5083. https://doi.org/10.1007/s00170-019-04911-8

29. Gatea S, Ou H, McCartney G (2018) Deformation and fracture characteristics of Al6092/SiC/17.5p metal matrix composite sheets due to heat treatments. Mater Charact 142:365-376. https://doi.org/10.1016/j.matchar.2018.05.050

30. Ma H, Zhao B, Ding K et al (2020) Influence of dealloying solution on the microstructure of nanoporous copper through chemical dealloying of Al75Cu25ribbons. J Mater Res 35:2610-2619. https://doi.org/10.1557/jmr.2020.69

31. Mohamed Abdul Ghani NNA, Saeed MA, Hashim IH (2017) Thermoluminescence (TL) response of silica nanoparticles subjected to 50 Gy gamma irradiation. Malaysian J Fundam Appl Sci 13:178180. https://doi.org/10.11113/mjfas.v13n3.593

32. Bajpai N, Tiwari A, Khan SA et al (2014) Effects of rare earth ions (Tb, Ce, Eu, Dy) on the thermoluminescence characteristics of sol-gel derived and $y$-irradiated $\mathrm{SiO} 2$ nanoparticles. Luminescence 29:669-673. https://doi.org/10.1002/bio.2604 
33. Portela R, Reinosa JJ, Pascual L Supplementary material Performance and stability of wet-milled CoAl 20 4, Ni / CoAl 204 and. 1-15

34. Phromma S, Wutikhun T, Kasamechonchung P et al (2020) Effect of calcination temperature on photocatalytic activity of synthesized TiO2 nanoparticles via wet ball milling sol-gel method. Appl Sci 10:. https://doi.org/10.3390/app10030993

35. Teo SH, Taufiq-Yap YH, Rashid U, Islam A (2015) Hydrothermal effect on synthesis, characterization and catalytic properties of calcium methoxide for biodiesel production from crude Jatropha curcas. RSC Adv 5:4266-4276. https://doi.org/10.1039/c4ra11936c

36. Bharali D, Devi R, Bharali P, Deka RC (2015) Synthesis of high surface area mixed metal oxide from the NiMgAl LDH precursor for nitro-aldol condensation reaction. New J Chem 39:172-178. https://doi.org/10.1039/c4nj01332h

37. Ravi Kumar K, Kiran K, Sreebalaji VS (2017) Micro structural characteristics and mechanical behaviour of aluminium matrix composites reinforced with titanium carbide. J Alloys Compd 723:795-801. https://doi.org/10.1016/j.jallcom.2017.06.309

38. Erdemir F, Canakci A, Varol T (2015) Microstructural characterization and mechanical properties of functionally graded Al2024/SiC composites prepared by powder metallurgy techniques. Trans Nonferrous Met Soc China (English Ed 25:3569-3577. https://doi.org/10.1016/S10036326(15)63996-6

39. Manohar G, Pandey KM, Maity SR (2021) Effect of sintering mechanisms on mechanical properties of AA7075/B4C composite fabricated by powder metallurgy techniques. Ceram Int. https://doi.org/https://doi.org/10.1016/j.ceramint.2021.02.073

40. Zhang X, Zhang Z, Liu Y et al (2019) High-performance B 4 C-TiB 2 -SiC composites with tuneable properties fabricated by reactive hot pressing. J Eur Ceram Soc 39:2995-3002. https://doi.org/10.1016/j.jeurceramsoc.2019.04.001

41. Manikandan R, Arjunan TV, Akhil AR (2020) Studies on micro structural characteristics, mechanical and tribological behaviours of boron carbide and cow dung ash reinforced aluminium (Al 7075) hybrid metal matrix composite. Compos Part B Eng 183:107668. https://doi.org/10.1016/j.compositesb.2019.107668

42. Bhowmik A, Dey D, Biswas A (2020) Comparative Study of Microstructure, Physical and Mechanical Characterization of SiC/TiB2 Reinforced Aluminium Matrix Composite. Silicon. https://doi.org/10.1007/s12633-020-00591-2

43. Meignanamoorthy $M$, Ravichandran M (2018) Synthesis, properties and microstructure of sintered and hot extruded boron carbide reinforced AA8079 (Al-Cu-Fe-Si-Zn) matrix composites. Mater Res Express 5:116508. https://doi.org/10.1088/2053-1591/aadc57

44. Fenghong C, Chang C, Zhenyu W et al (2019) Effects of Silicon Carbide and Tungsten Carbide in Aluminium Metal Matrix Composites. Silicon 11:2625-2632. https://doi.org/10.1007/s12633-018$0051-6$ 
45. Alihosseini H, Dehghani K, Kamali J (2017) Microstructure characterization, mechanical properties, compressibility and sintering behavior of Al-B4C nanocomposite powders. Adv Powder Technol 28:2126-2134. https://doi.org/10.1016/j.apt.2017.05.019

46. Sudarshan SMK (2008) Synthesis of fly ash particle reinforced A356 Al composites and their characterization. Mater Sci Eng A 480:117-124. https://doi.org/10.1016/j.msea.2007.06.068

47. Michael Rajan HB, Ramabalan S, Dinaharan I, Vijay SJ (2013) Synthesis and characterization of in situ formed titanium diboride particulate reinforced AA7075 aluminum alloy cast composites. Mater Des 44:438-445. https://doi.org/10.1016/j.matdes.2012.08.008

48. Pramanik A, Littlefair G, Basak AK (2015) Materials and Manufacturing Processes Weldability of Duplex Stainless Steel. 37-41. https://doi.org/10.1080/10426914.2015.1019126

49. Wu YY, Tsui WC, Liu TC (2007) Experimental analysis of tribological properties of lubricating oils with nanoparticle additives. 262:819-825. https://doi.org/10.1016/j.wear.2006.08.021

50. Sunqing Q, Junxiu D, Guoxu C (2000) Tribological properties of CeF 3 nanoparticles as additives in lubricating oils. 99-102

51. Ravindran P, Manisekar K, Narayanasamy R, Narayanasamy P (2013) Tribological behaviour of powder metallurgy-processed aluminium hybrid composites with the addition of graphite solid lubricant. Ceram Int 39:1169-1182

52. Sankara Raju RS, Panigrahi MK, Ganguly RI, Srinivasa Rao G (2019) Tribological behaviour of al1100-coconut shell ash (CSA) composite at elevated temperature. Tribol Int 129:55-66. https://doi.org/10.1016/j.triboint.2018.08.011

53. Chin F, Spikes HA (2003) Mechanism of Action of Colloidal Solid Dispersions. 125:552-557. https://doi.org/10.1115/1.1537752

54. Salehi M (2000) Delamination Wear Mechanism. 13:37-50

55. Huang W, Lin Q, Zhang X (2016) Investigation of tribological properties of magnesium alloys under dry sliding and lubrication condition. 225:35-42. https://doi.org/10.1177/13506501JET795

\section{Figures}



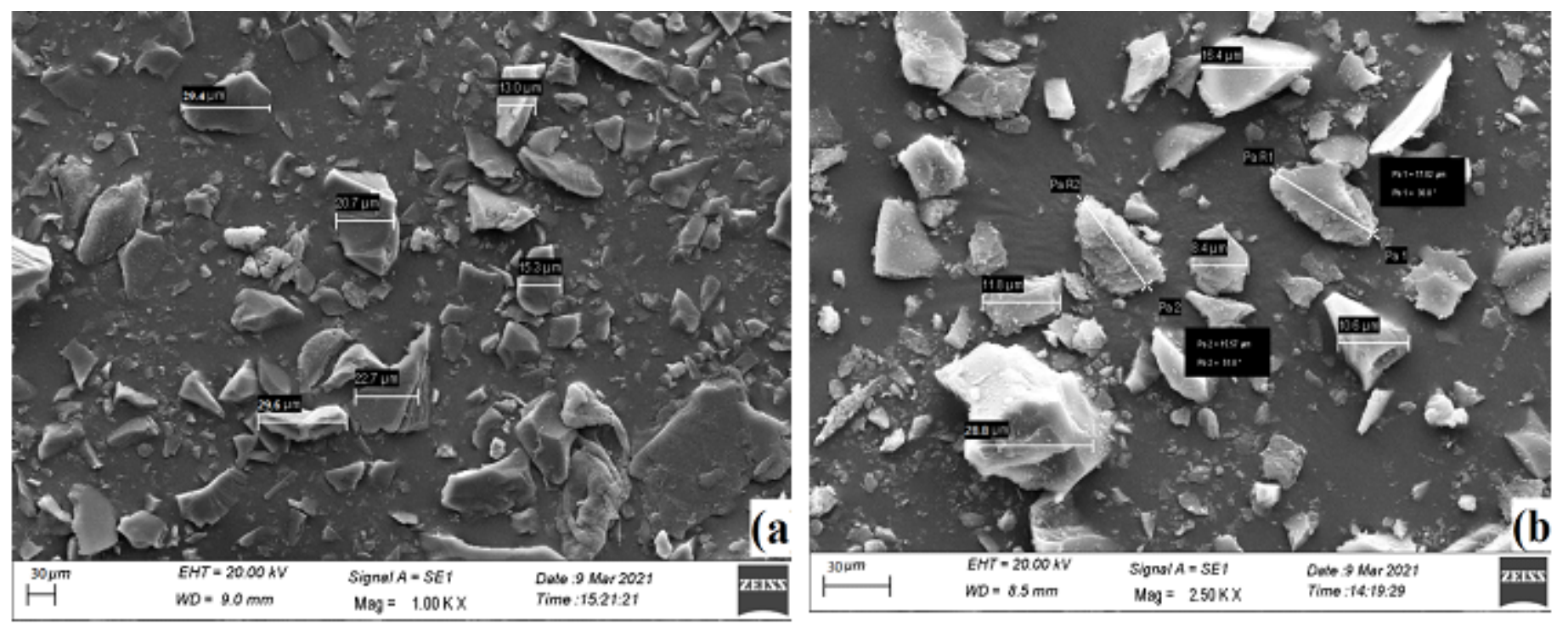

\section{Figure 1}

Particle sizes of (a) SiC reinforcement,(b) Kaoline reinforcement Aluminium Powder

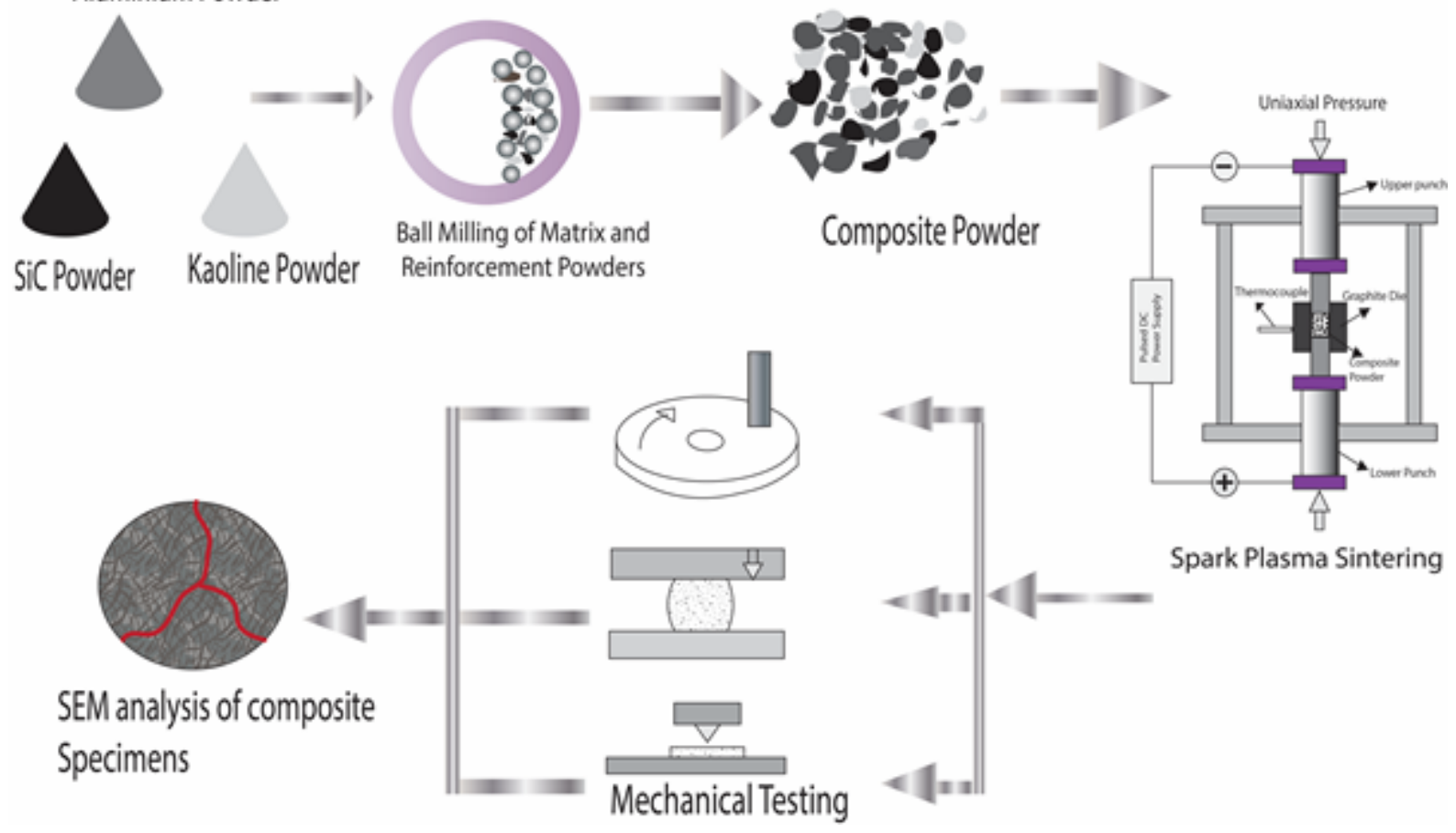

Figure 2

Schematic diagram for fabrication of HMMC specimen 

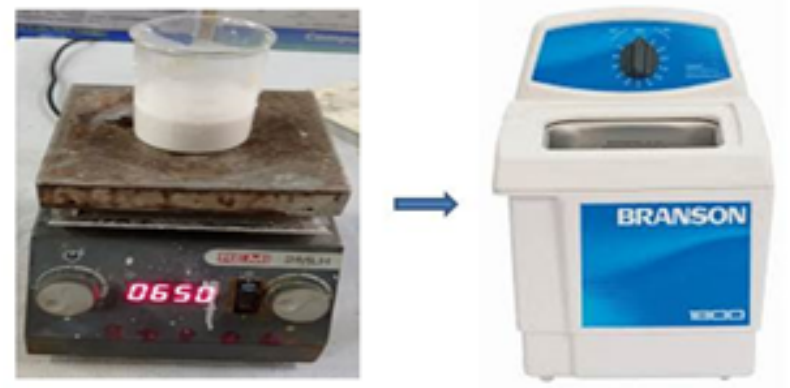

Ultrasonic Sonicator

Magnetic Stirrer

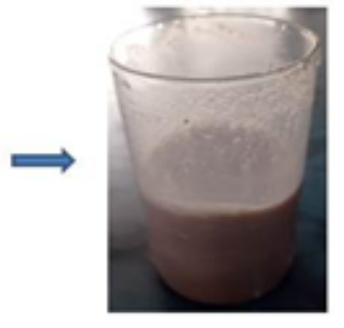

SiC nanofluids

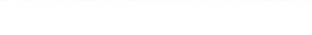

\section{Figure 3}

Schematic diagram for Preparation of SiC nanofluids

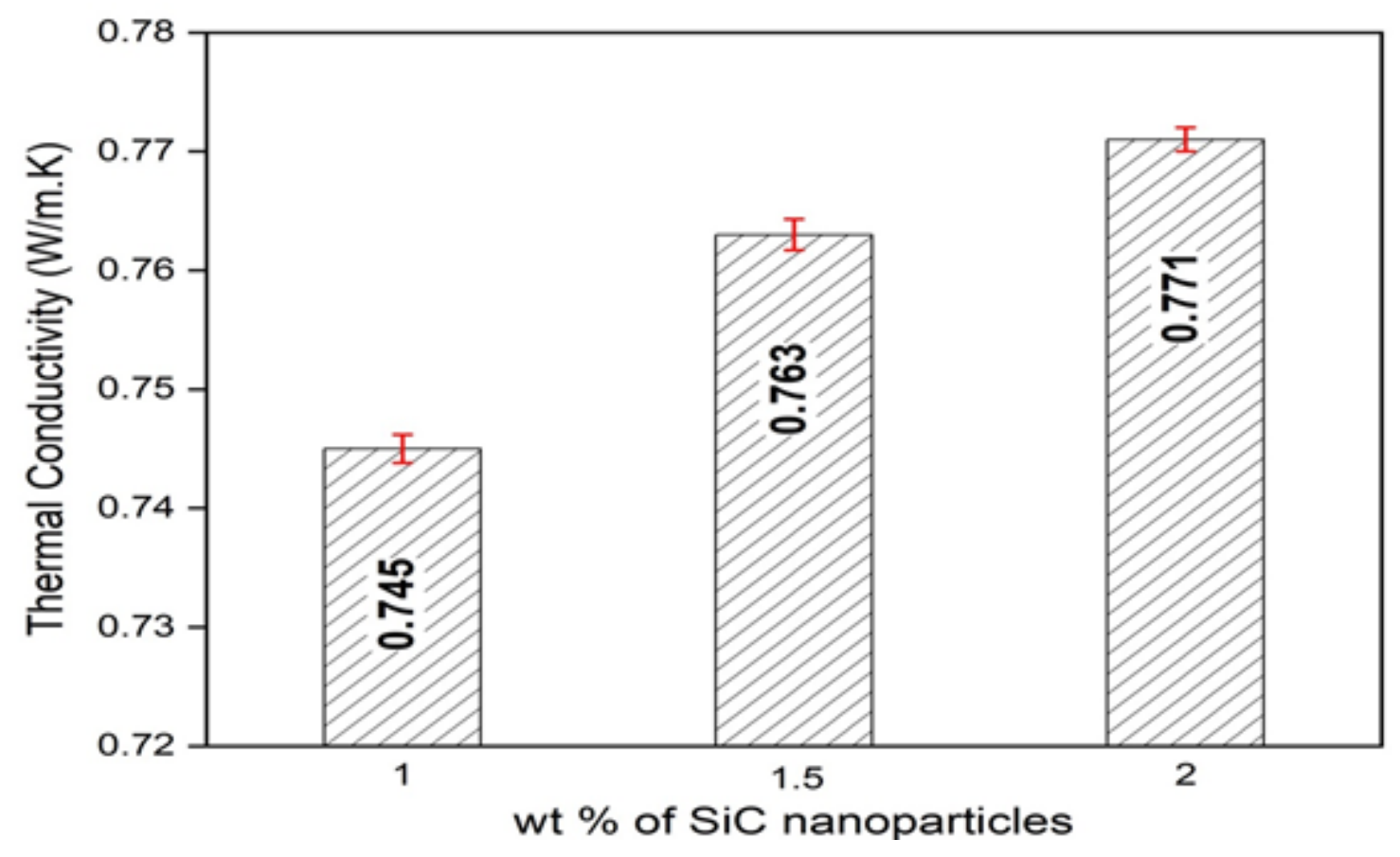

\section{Figure 4}

Variation of Thermal conductivity of nanofluids with wt \% of SiC nanoparticles 


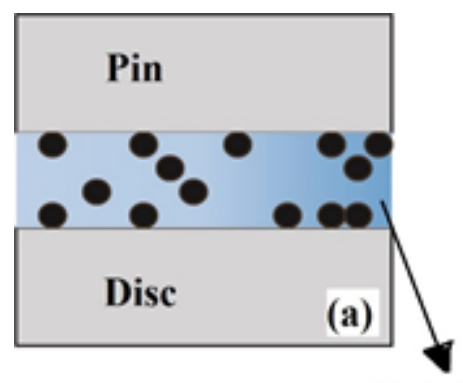

Soluble Oil

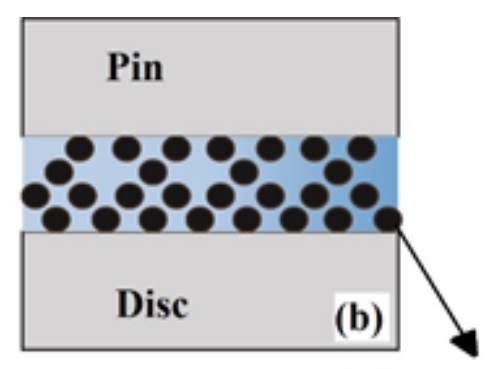

SiC nanoparticles

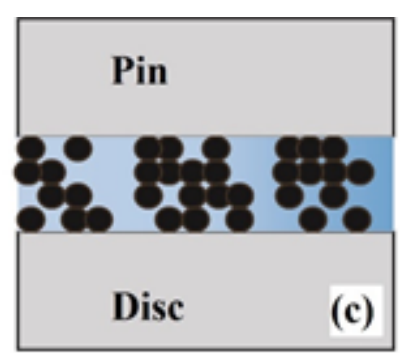

(c)

\section{Figure 5}

(a) less than 2 wt.\% SiC nanoparticles (Non-uniform distribution), (b) 2 wt.\% SiC nanoparticles (uniform distribution), (c) more than $2 \mathrm{wt}$ \% SiC nanoparticles (Agglomerations of SiC nanoparticles).
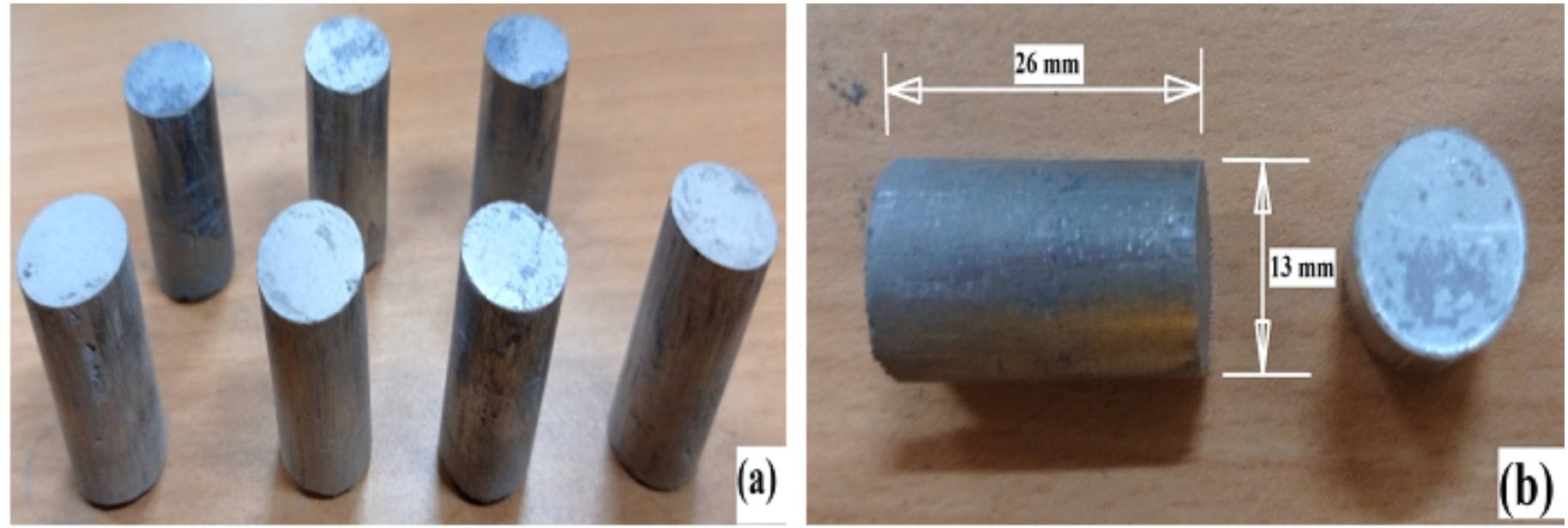

(a)

(b)

Figure 6

Fabricated HMMC specimens for (a) Tribology test and (b) Compression test 

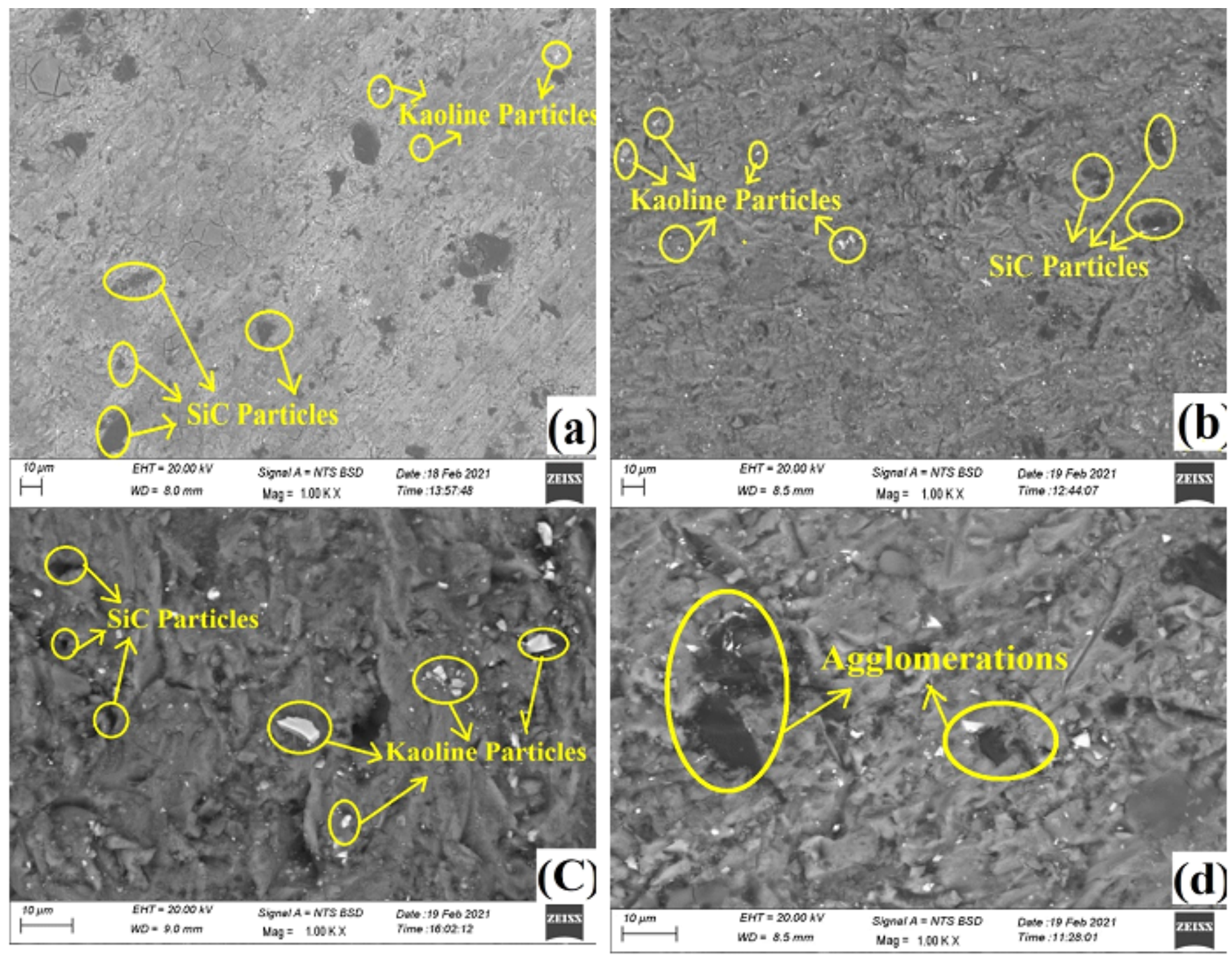

\section{Figure 7}

SEM micrographs for (a) Al-10\% SiC-2\% Kaoline, (b) Al-10\% SiC-4\% Kaoline, (c) Al-10\% SiC-6\% Kaoline, (d) Al-10\% SiC-8\% Kaoline 


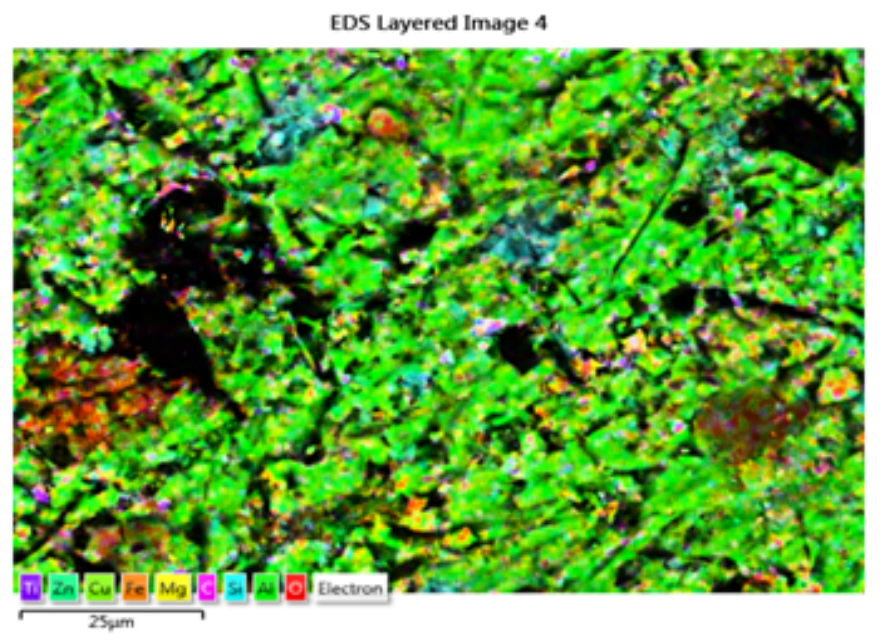

Al $K \alpha 1$

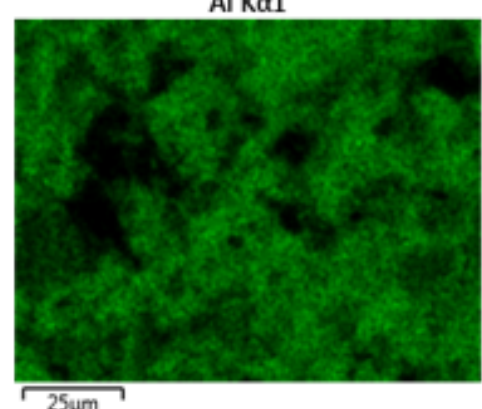

$\mathrm{Mg} \mathrm{Ka12}$

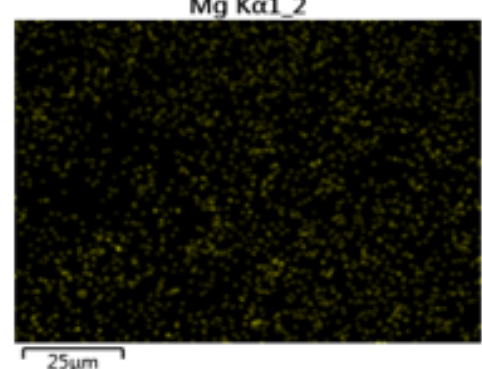

Fe K $\alpha 1$

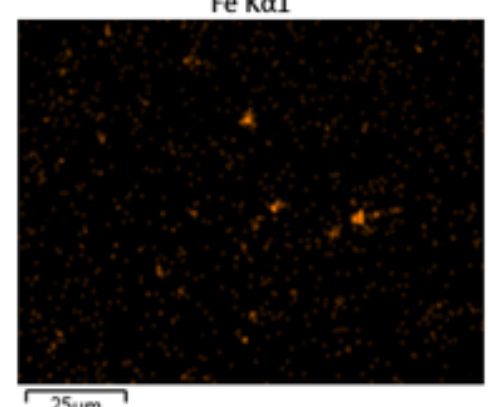

$\longdiv { 2 5 \mu m }$
$\mathrm{OK} \alpha 1$

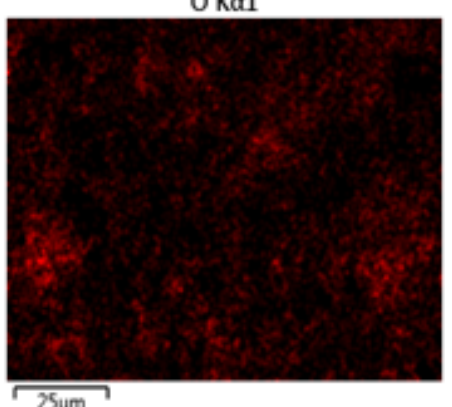

C Ka1_2

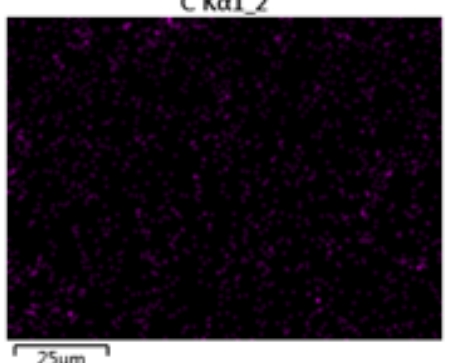

$\mathrm{Cu} \mathrm{K \alpha 1}$

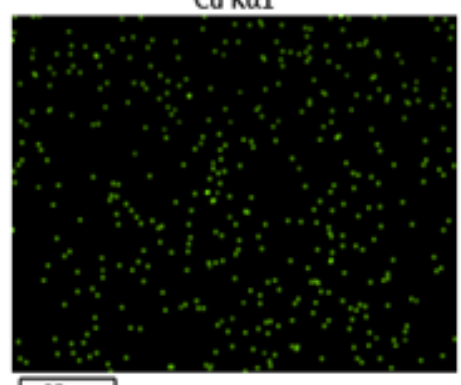

$\longdiv { 2 5 \mu \mathrm { m } }$
Si $K \alpha 1$

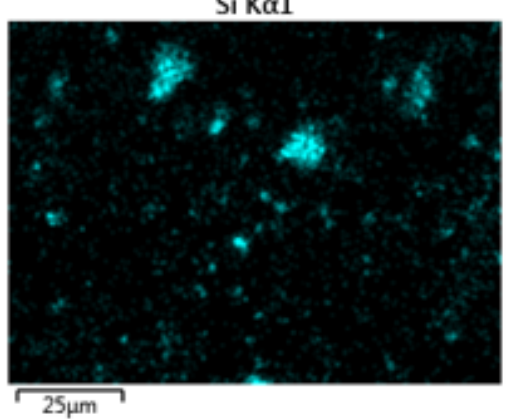

$\mathrm{Ti} \mathrm{K} \alpha 1$

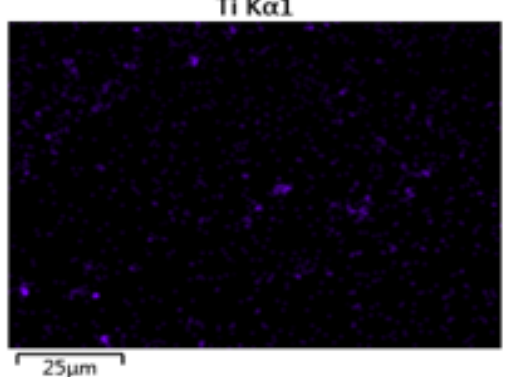

$\mathrm{Zn} \mathrm{K \alpha 1}$

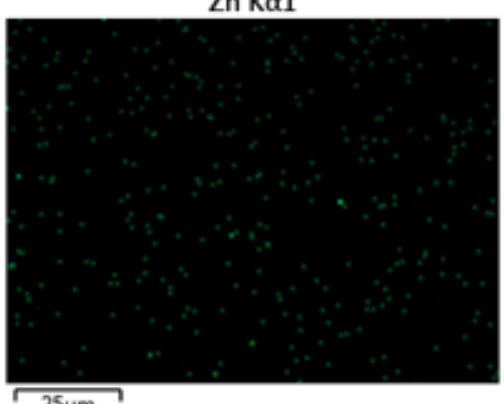

Figure 8

Elemental mapping for Al-10\% SiC-8 \% Kaoline HMMC 


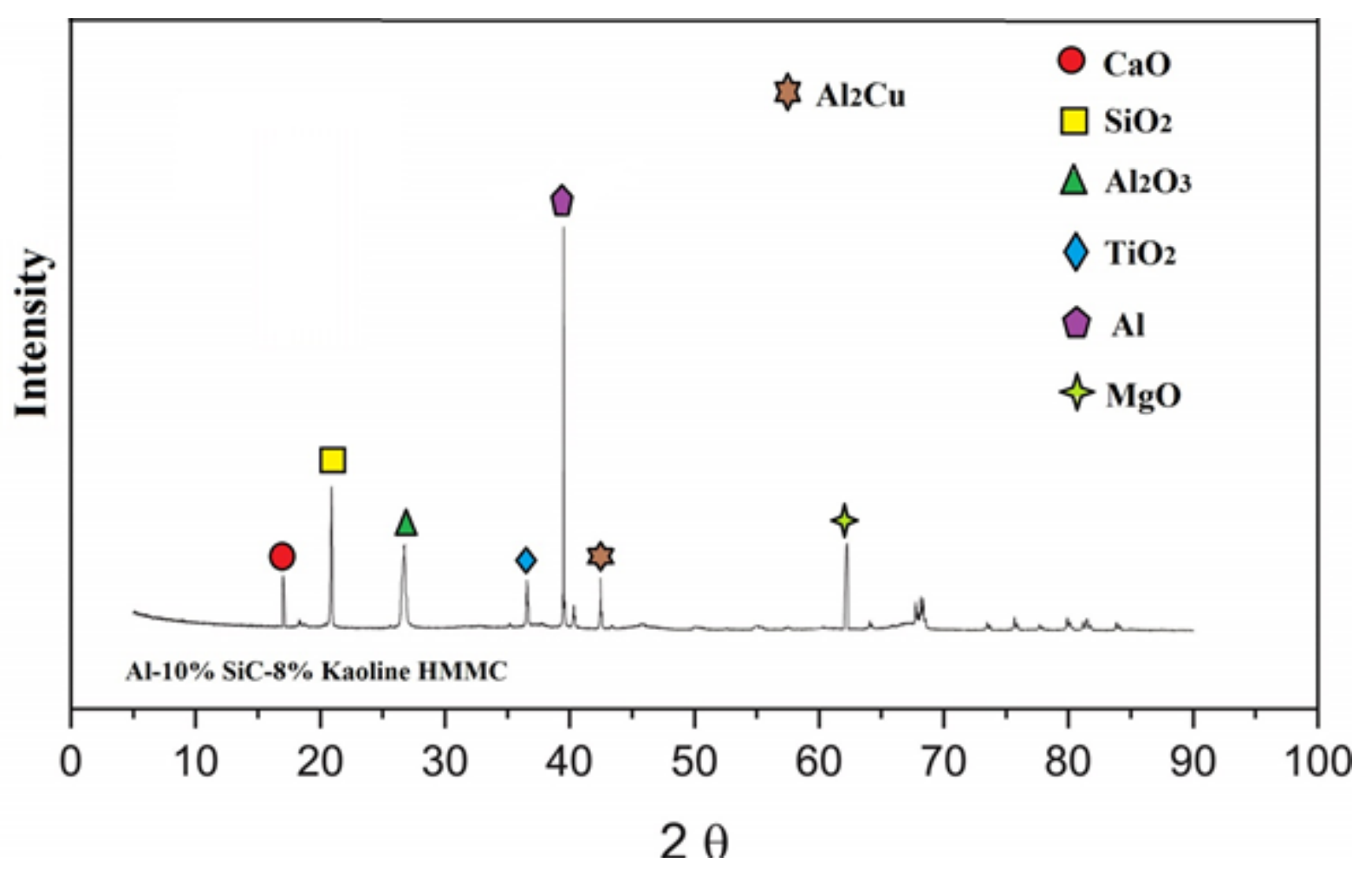

Figure 9

XRD pattern for Al-10\% SiC-8\% Kaoline SPS HMMC specimen

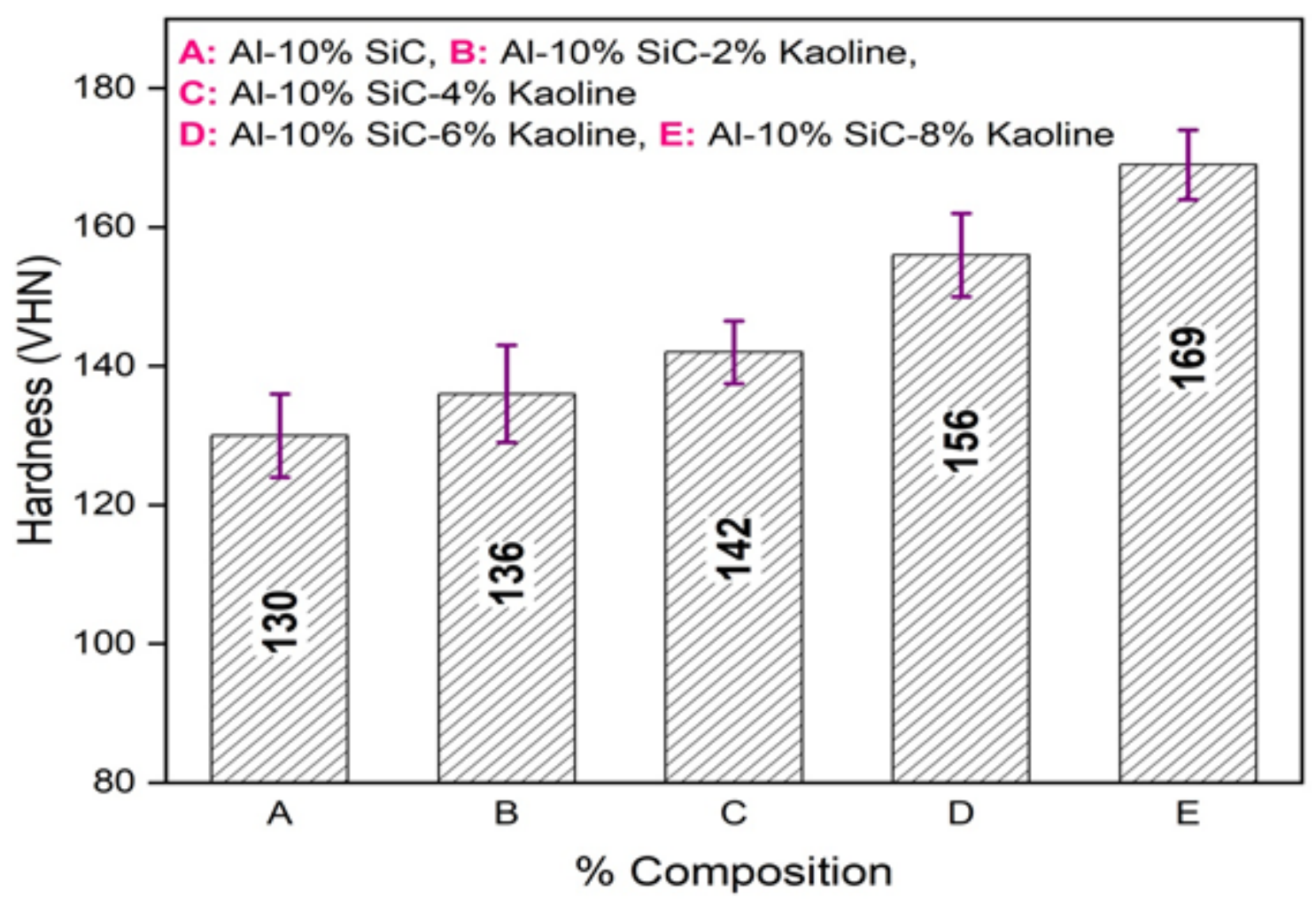

Figure 10

Variation of the hardness of HMMC with \% of kaoline reinforcement 


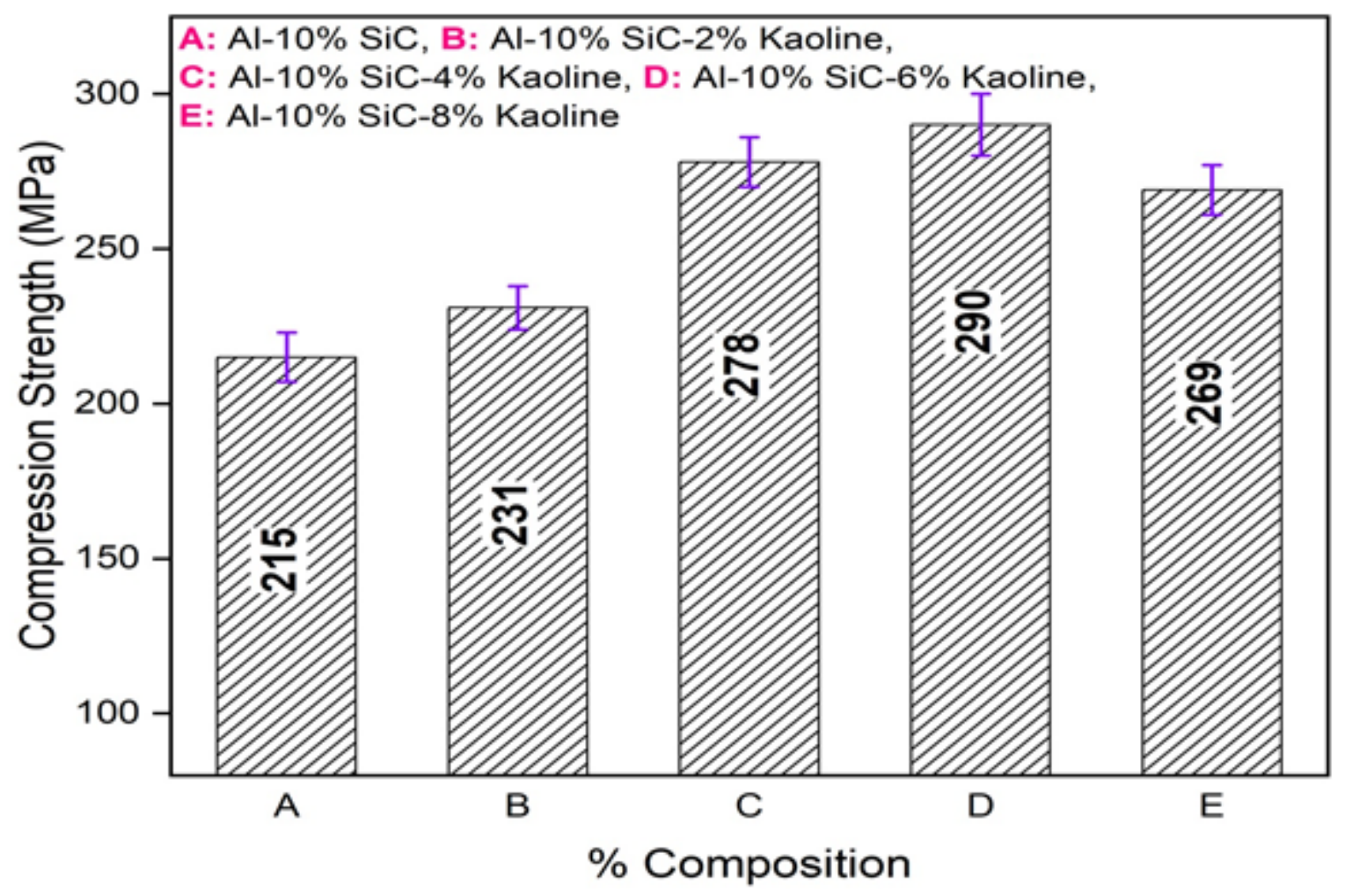

Figure 11

Variation of Compression strength of HMMC with \% of kaoline reinforcement

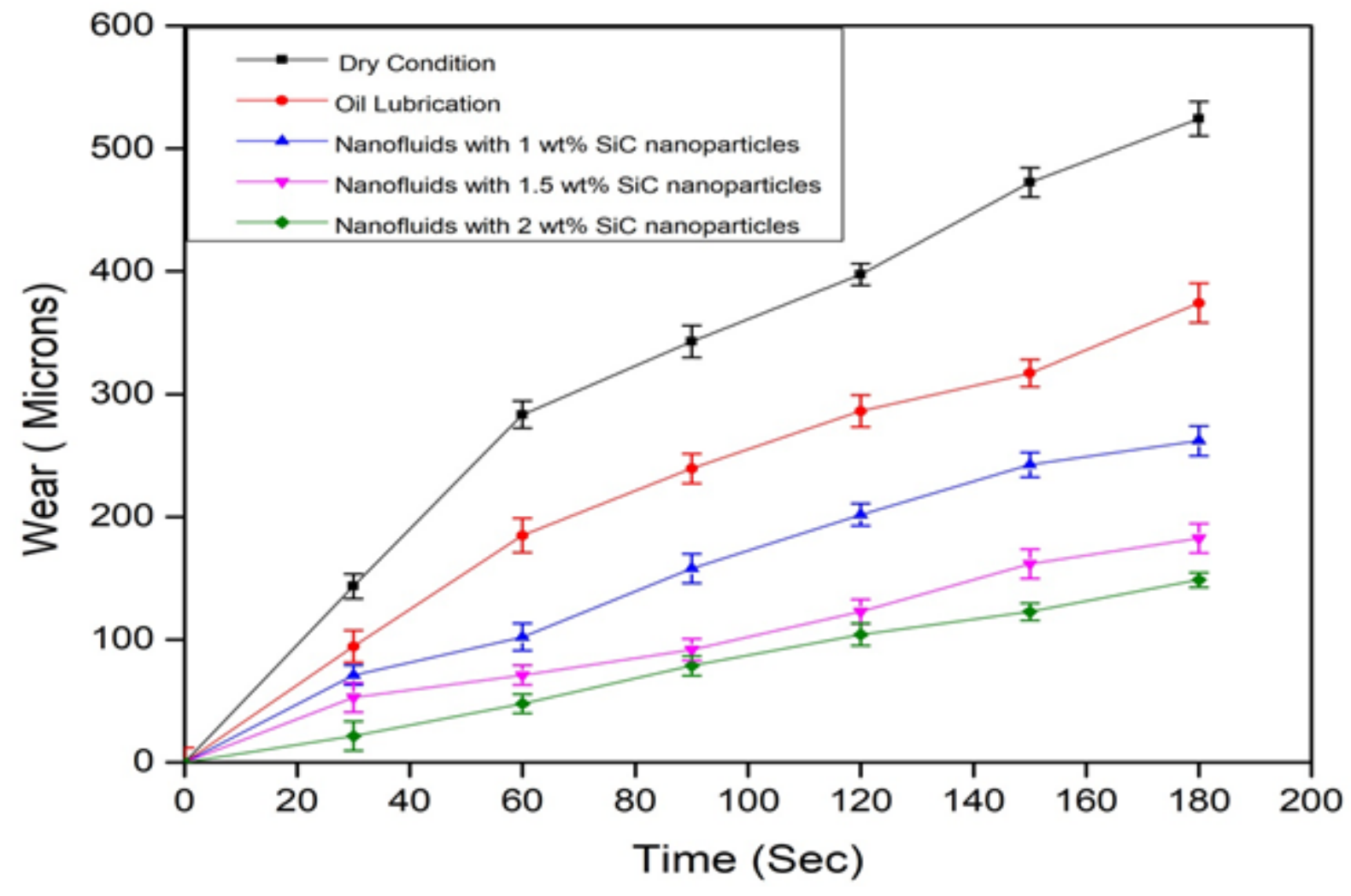

Figure 12

Variation of wear for HMMC pin with time under different lubricating conditions 


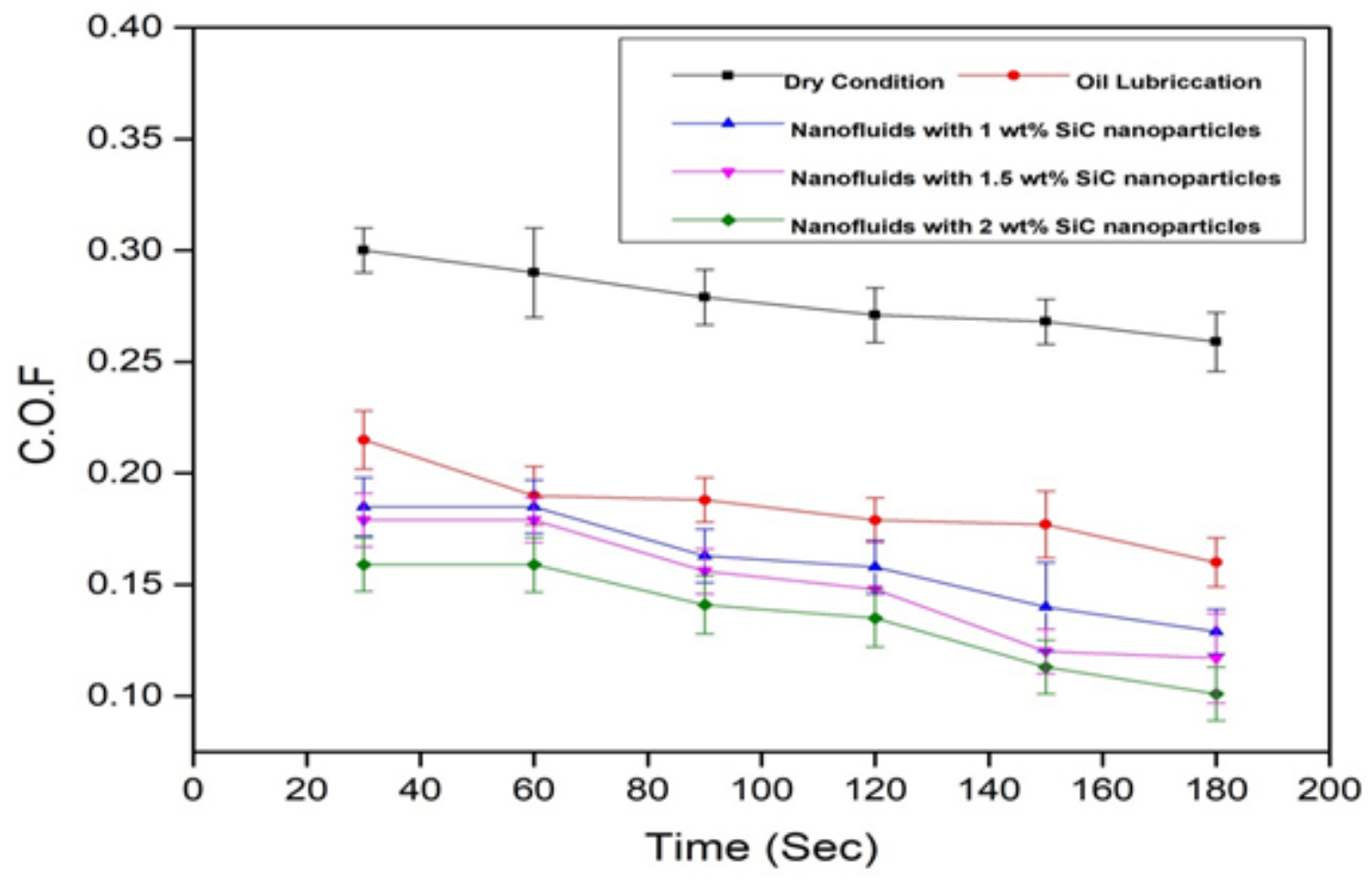

Figure 13

Variation of C.O.F for HMMC pin under different lubricating conditions 

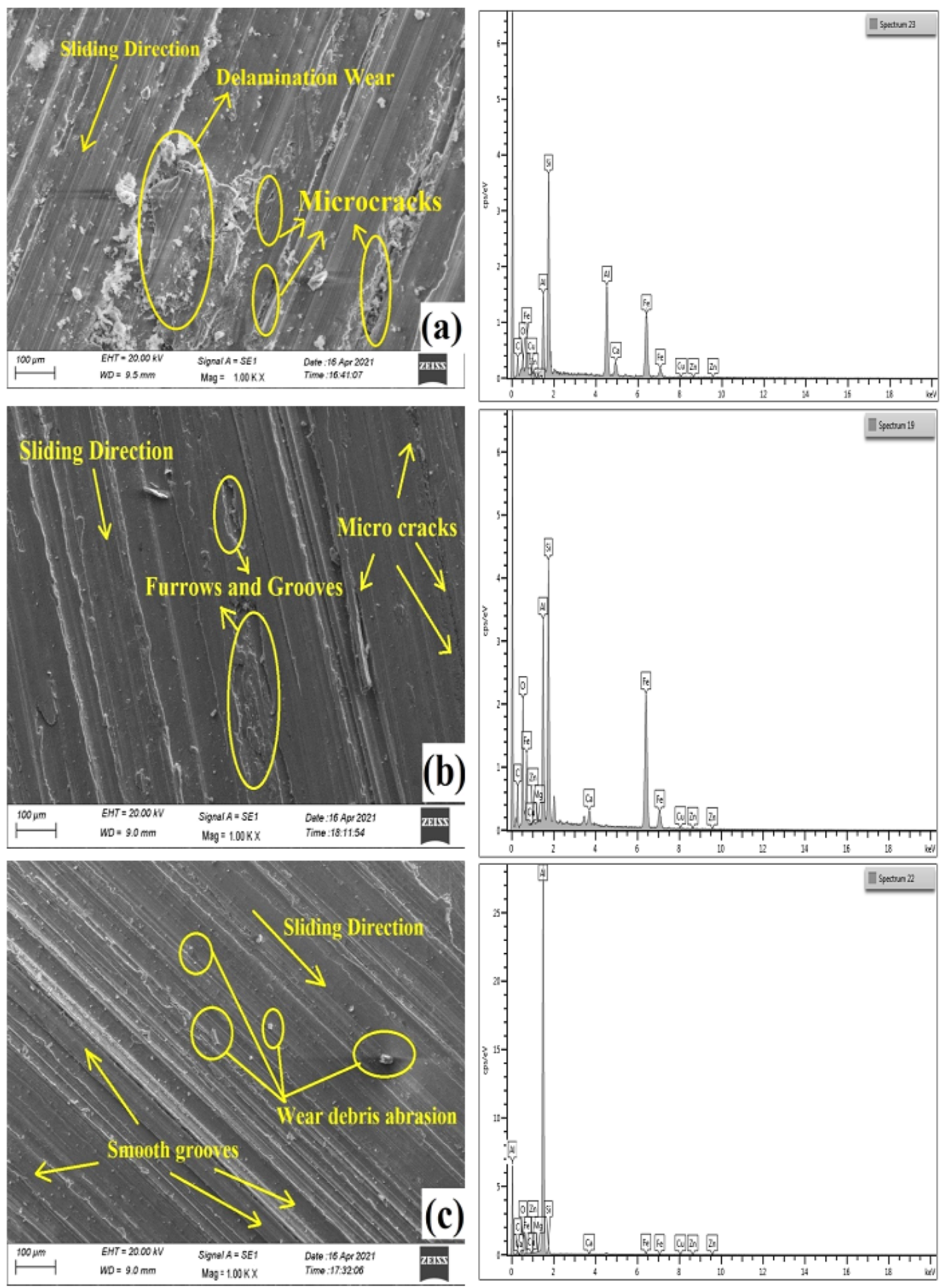

\section{Figure 14}

SEM and EDX images of HMMC pin after for 180 s under (a) Dry, (b) Oil, (c) $2 \%$ SiC-nanofluid lubricating conditions 